\title{
PSTRATEGI BISNIS RSU PKU MUHAMMADIYAH BLORA MELALUI PEMETAAN FAKTOR INTERNAL DAN EKSTERNAL
}

\author{
AisyahLahdji \\ Universitas Muhammadiyah Semarang \\ Email: lahdjiaa@yahoo.com
}

\begin{abstract}
Abtrak
Lingkungan bisnis yang terus berubah menuntut Rumah Sakit (RS) untuk menyesuaikan diri. Penyusunan rencana strategi diperlukan sebagai upaya RS untuk menjawab tantangan perubahan. Oleh sebab itu, kajian yang disoroti dalam penelitian ini berkaitan dengan pengembangan strategi bisnis pada Rumah Sakit Umum (RSU) PKU Muhammadiyah Blora. Penelitian ini merupakan sebuah penelitian operasional riset yang dilakukan dengan pendekatan deskriptif, mengenai Perencanaan Strategis Untuk Pelayanan di Rumah Sakit Umum (RSU) PKU Muhammadiyah Blora Tahun 2016 - 2020. Hasil penelitian ini mengarahkan bahwa RSU PKU Muhammadiyah Blora perlu mengembangkan sebuah Rencana Strategi Pelayanan. Rencana Strategi Pelayanan yang dikembangkan mengacu pada hasil Focus Group Discusion (FGD) yang telah dilakukan dalam penelitian ini yang telah memetakan kekuatan dan kelemahan yang dimiliki oleh RSU PKU Muhammadiyah Blora serta peluang dan ancaman yang dihadapi oleh RSU PKU Muhammadiyah Blora. Adapun Rencana Strategi Pelayanan yang dirumuskan dengan memperkuat SDM yang ada melalui kegiatan pendidikan dan pelatihan bagi tenaga kesehatan dan non kesehatan, memperluas jejaring kemitraan dengan dokter spesialis untuk meningkatkan kualitas pelayanan medis, secara berkala menambah kapasitas tempat tidur, meningkatkan kualitas pelayanan pendukung seperti laboratorium, rekam medis, rehabilitasi medis, dan sarana pengelolaan limbah. Rencana Strategi Pelayanan yang telah disusun tersebut memerlukan komitmen yang kuat dari semua lini RSU PKU Muhammadiyah Blora agar tujuan yang telah direncanakan dalam strategi pelayanan dapat tercapai.
\end{abstract}

Kata Kunci : Perencanaan strategis, strategi terpilih, rencana strategi pelayanan 



\begin{abstract}
The changing business environment demands Hospital to adjust. The arrangement of a strategic planning is required as the hospital effort to answer the challenges of change. Therefore, the study highlighted in this research relates to the development of business strategy at the General Hospital of PKU Muhammadiyah Blora. This research is an operational research conducted with descriptive approach on the Service Strategy Planning in the Public Hospital (RSU) PKU Muhammadiyah Blora Year 2016 - 2020. The result of this research directs that RSU PKU Muhammadiyah Blora needs to develop Service Strategy Planning. The developed Service Strategy Planning refers to the results of Focus Group Discussion (FGD) done in this research which had mapped out the strengths and weaknesses owned by General Hospital of PKU Muhammadiyah Blora and the opportunities and threats faced by General Hospital of PKU Muhammadiyah Blora. The formulated Service Strategy Planning include improving the quality of human resources through education and training programs, specialist scholarship programs for physicians, increasing partnerships with specialist physician partners, adding capacity / number of beds, as well as improving service quality. The implementation of developed Service Strategy Planning requires a commitment from all levels of staff in General Hospital of PKU Muhammadiyah Blora.
\end{abstract}

Keywords : Strategic Planning, chosen strategy, service strategy planming

\section{PENDAHULUAN}

Rumah Sakit sebagai produsen layanan kesehatan harus mampu mengantisipasi perubahan dan mengetahui posisinya untuk mengambil keuntungan dari peluang yang ada dan menjauhi ancaman-ancaman yang akan datang. Perencanaan strategis yang dimiliki Rumah Sakit (RS) memungkinkan RS tersebut untuk memimpin dalam pengelolaan rumah sakit dan sesuatu yang diharapkan di masa depan dapat terwujud. Perencanaan strategis mempunyai peranan yang penting untuk dapat menjawab tuntutan lingkungan di sekitar RS tersebut ${ }^{1}$.

Keterbatasan sumber daya yang dimiliki oleh RS menempatkan perlunya aspek manajemen dan operasional dikelola dengan baik mengingat tuntutan lingkungan yang mencakup mutu, efisiensi, equity, dan kebijakan otonomi yang terus berubah. Oleh sebab itu, masa depan organisasi khususnya RS menentukan sebuah perencanaan strategis yang tepat. Perencanaan strategis memungkinkan RS melakukan pendekatan secara sistematis, logis, dan rasional ${ }^{2}$.

Perencanaan strategis perlu ditetapkan terlebih dahulu agar RS memiliki arahan dalam menjalankan kegiatannya sekaligus menjadi acuan dalam mencapai tujuan yang telah ditetapkan. Evaluasi berkala terhadap hasil kegiatan juga dimungkinkan dengan adanya perencanaan strategis ${ }^{3}$.
Perencanaan Strategis Rumah Sakit menyebabkan kinerja Rumah Sakit menjadi lebih baik, melalui analisis lingkungan internal maupun eksternal rumah sakit sehingga bisa mengidentifikasi secara maksimal dan melalui isu-isu strategis yang berkaitan dengan apa yang dihadapi oleh RSU PKU Muhammadiyah Blora ${ }^{4}$.

Pengukuran kinerja tersebut dapat diukur dengan pendekatan Balanced Scorecard, yang meliputi 4 perspektif yaitu perspektif pembelajaran dan pertumbuhan, perspektif internal bisnis, perspektif pelanggan dan perspektif keuangan ${ }^{5,6,7}$.

Hasil survai pendahuluan yang dilakukan di RSU PKU Muhammadiyah Blora sebagai RS Tipe D dengan jumlah tempat tidur sebanyak 50 pada tahun 2011-2013 menunjukkan terjadinya penurunan jumlah pasien rawat jalan maupun pasien rawat inap di. Hal ini menjadi indikasi atas penataan manajemen yang belum optimal. Oleh sebab itu, perlu penelitian yang mengkaji faktor internal dan eksternal RS untuk menentukan perencanaan strategis yang dapat menjawab permasalahan yang ditemukan di RSU PKU Muhammadiyah Blora. 


\section{TINJAUAN PUSTAKA}

\section{Rumah Sakit}

Definisi Rumah Sakit menurut Undang-Undang Republik Indonesia Nomor 44 Tahun 2009 tentang Rumah Sakit Pasal 1 Ayat 1 adalah institusi pelayanan kesehatan yang menyelenggarakan pelayanan kesehatan perorangan secara paripurna yang menyediakan pelayanan rawat inap, rawat jalan dan gawat darurat. RS juga memiliki definisi sebagai tempat menyelenggarakan upaya kesehatan yaitu setiap kegiatan untuk memelihara dan meningkatkan kesehatan serta bertujuan untuk mewujudkan derajat kesehatan yang optimal bagi masyarakat ${ }^{8}$. Upaya kesehatan dilakukan dengan pendekatan pemeliharaan, peningkatan kesehatan (promotif), pencegahan penyakit (preventif), penyembuhan penyakit (kuratif) dan pemulihan (rehabilitatif) yang dilaksanakan secara serasi dan terpadu serta berkesinambungan.

\section{Statistik Unit Rawat Inap (RANAP) Rumah Sakit}

Indikator yang biasa dihasilkan dari statistik rawat inap diantaranya adalah"

1. Bed occupancy rate (BOR), menunjukkan prosentase pemakaian tempat tidur yang merupakan indikator cakupan dan efisiensi penggunaan tempat tidur di URI. Standar efisiensi BOR adalah 75\%-85\% apabila BOR $>85 \%$ berarti tempat tidur yang terpakai di RS tersebut hampir penuh sesak.

2. Bed Turn Over (BTO), yaitu jumlah pasien yang menggunakan satu tempat tidur merupakan indikator cakupan dan efisiensi penggunaan tempat tidur di URI. Standar efisiensi BTO adalah 30 pasien.

3. Average Length of Stay (AVLOS), yaitu rata-rata jumlah lama hari dirawat pasien merupakan indikator efisiensi penggunaan tempat tidur di URI tidak termasuk bayi lahir. Standar efisien AVLOS adalah 3-12 hari dan AVLOS dianjurkan serendah mungkin tanpa mempengaruhi kualitas layanan perawatan.

4. Turn Over Interval (TOI), yaitu rata-rata selang waktu hari tempat tidur tidak dipakai, merupakan indikator efisiensi penggunaan tempat tidur di URI. Standar efisiensi TOI adalah 1-3 hari.

5. Gross Death Rate (GDR), yaitu angka kematian kasar di URI, merupakan indikator mutu pelayanan di RANAP

6. Net Death Rate (NDR), yaitu angka kematian bersih di RANAP, merupakan indikator mutu pelayanan di RANAP

\section{Perencanaan Strategi}

Pemahaman perencanaan strategis diperlukan karena sebagai pedoman untuk melaksanakan kegiatan guna mencapai tujuan. Perencanaan strategik (strategic planning) merupakan alat penterjemah dari keluaran sistem perumusan strategi. Dalam perencanaan strategi harus memahami konsep visi, misi, tujuan, keyakinan dasar, nilai dasar dan startegi Rumah Sakit ${ }^{10}$.

Perencanaan strategi adalah serangkaian keputusan dan tindakan strategis dengan mempertimbangkan pengaruh lingkungan eksternal dan internal untuk merumuskan formulasi dan implementasi lintas sistem fungsional yang didalamnya mencakup keselarasan kebijakan dan tindakan di seluruh tingkat manajemen ${ }^{11}$.

Perencanaan strategis dengan mempertimbangkan pengaruh lingkungan internal (kekuatan dan kelemahan) dan eksternal (peluang dan ancaman) dapat mengidentifikasi berbagai faktor utama secara sistematis untuk merumuskan kegiatan strategis yang diperlukan ${ }^{12}$.

\section{METODE PENELITIAN}

\section{Jenis Penelitian}

Penelitian ini merupakan penelitian operasional (operational research) dengan analisis data kualitatif. Menggunakan analisis data primer dan data sekunder. Data primer dikumpulkan secara kualitatif dengan melakukan wawancara mendalam (in-depth interview) dan teknik Consenssus Discussion Making Group (CDMG) sedangkan data sekunder dikumpulkan melalui deskresearch. 


\section{Subyek Penelitian}

Penelitian ini merupakan sebuah penelitian kualitatif. Oleh sebab itu penelitian ini tidak menggunakan populasi atau sampel sebagai sumber data namun menggunakan subyek penelitian atau informan yang dianggap memiliki data yang diperlukan dalam penelitian ini, meliputi Pimpinan RS, Kepala Bidang, Kepala Bagian, Kepala Unit, Kepala Ruang.

\section{Pengumpulan Data}

Data yang dikumpulkan dalam penelitian ini terdiri dari dua kategori, yaitu data primer dan data sekunder. Data primer diperoleh melalui wawancara kepada pimpinan RS sedangkan data sekunder diperoleh melalui pemanfaatan data-data internal RS seperti data kunjungan pasien rawat jalan, data kunjungan pasien rawat inap, data pelayanan laboratorium.

\section{Analisis Data}

Data primer dan sekunder yang dikumpulkan dalam penelitian ini selanjutnya dianalisis dengan analisis SWOT (Strengths, Weaknesses, Opportunities, and Threats). Analisis SWOT ini berguna untuk merumuskan Rencana Strategi Pelayanan RSU PKU Muhammadiyah Blora. Langkah pertama yang dilakukan dalam analisis SWOT adalah melakukan pemetaan terhadap lingkungan internal dan eksternal RSU PKU Muhammadiyah Blora. Langkah kedua adalah mengkategorikan temuan-temuan ke dalam kekuatan, kelemahan, peluang, dan ancaman. Langkah ketiga, adalah menentukan skor atas temuan-temuan tersebut. Langkah keempat, adalah membuat matriks SWOT yang akan membantu peneliti dalam merumuskan strategi yang perlu atau harus dijalankan dengan cara mengelompokkan masing - masing problem utama ke dalam tabel ${ }^{13}$.

\section{ANALISIS DATA}

\section{Kekuatan (Strengths)}

Temuan faktor kekuatan yang dimiliki RS PKU Muhammadiyah Blora mencakup jumlah pasien rawat jalan dan inap meningkat; kecukupan jumlah pelayanan penunjang, jumlah karyawan, total asset, jumlah tenaga medis, paramedis, paramedis non perawatan, non medis; secara geografis jauh dari competitor dan dibatasi oleh empat kabupaten, serta merupakan amal usaha Muhammadiyah.

\section{Kelemahan (Weaknesses)}

Faktor-faktor kelemahan yang ditemukan di RS PKU Muhammadiyah Blora mencakup belum memadainya sarana dan prasarana (sarana bangunan, peralatan medis dan penunjang medis, dokter umum, dokter spesialis, pelayanan medis dan pelayanan penunjang medis), serta Visi dan Misi yang kurang operasional dengan kemampuan PKU Muhammadiyah Blora saat ini.

\section{Peluang (Opportunities)}

Peluang yang dimiliki RS PKU Muhammadiyah Blora yang berhasil dipetakan dalam penelitian ini mencakup pertumbuhan jumlah penduduk, jumlah penduduk miskin, kunjungan pasien rawat jalan, angka kesakitan, jumlah peserta Badan Penyelenggara Jaminan Sosial Non Penerima Bantuan Iuran (BPJS Non PBI), jumlah penduduk dengan BPJS PBI.

\section{Ancaman (Threats)}

Faktor keempat berkaitan dengan ancaman yang dihadapi oleh RS PKU Muhammadiyah Blora. Adapun factor ancaman tersebut meliputi munculnya RS-RS baru di sekitar wilayah Blora, fasilitas yang dimiliki RS pesaing lebih lengkap, Regulasi/aturan yang membatasi dokter untuk berpraktek maksimal pada 3 RS, terjadinya penurunan jumlah kunjungan Pasien BPJS Non PBI ke Poliklinik RS PKU Muhammadiyah Blora oleh peningkatan pemanfaatan pelayanan fisioterapi oleh pasien BPJS PBI di RS PKU Muhammadiyah Blora namun pemanfaatan pelayanan fisioterapi di RS PKU Muhammadiyah Blora secara umum mengalami penurunan, Proyeksi pertumbuhan jumlah penduduk miskin mengalami penurunan merupakan hal yang perlu diperhatikan mengingat segmen pasar yang disasar oleh RS PKU Muhammadiyah Blora saat ini adalah penduduk ekonomi menengah ke bawah atau peserta BPJS PBI, Proyeksi jumlah peserta BPJS non PBI yang mengalami penurunan perlu mendapat perhatian karena dapat mengurangi jumlah kunjungan pasien, Jumlah 
tenaga medis (dokter umum dan spesialis) yang dimiliki pesaing lebih banyak dibandingkan jumlah tenaga

tahun 2004 tentang SJSN dimana pembayaran fasilitas kesehatan rujukan tingkat lanjutan dibayarkan melalui sistem INA CBG's.

Skor pembobotan nilai analisis SWOT berdasarkan faktor eksternal dan internal diperoleh skor sebagai berikut :factor kekuatan $=2,137$; factor kelemahan $=$ 1,231 , factor peluang $=1,813$ dan factor ancaman $=$ 1,507 .

Perpotongan keempat garis factor kekuatan, kelemahan, peluang dan ancaman diperoleh koordinat sebagai berikut :

Skor Kekuatan - Skor Kelemahan :Skor Peluang - Skor Ancaman 2

$\frac{2,137-1,231}{2}: \frac{1,813-1,507}{2}$

$(0,453: 0,153)$

Skor pembobotan yang ada selanjutnya dituangkan dalam gambar analisis diagram seperti terlihat pada gambar 1 .

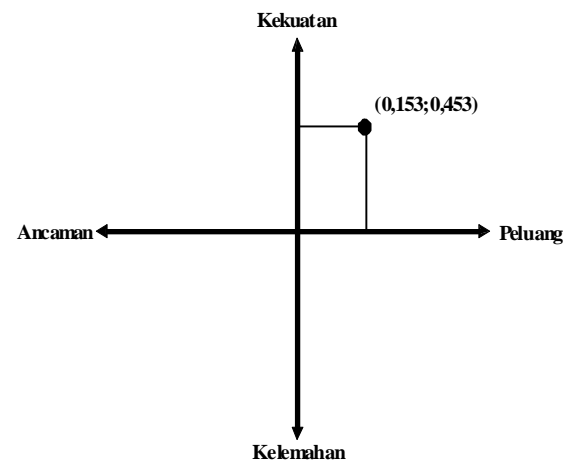

Gambar 1. Grafik Analisis SWOT

Mengacu pada skor kekuatan, kelemahan, peluang dan ancaman RS PKU Muhammadiyah Blora maka dapat ditentukan posisi RS PKU Muhammadiyah Blora dalam Grafik SWOT pada koordinat $(0,153$ : 0,453) yang berarti bahwa RS PKU Muhammadiyah Blora berada pada kuadran I, yaitu Strategi Agresif, strategi ini menunjukkan situasi yang sangat menguntungkan.

\section{Pengembangan Strategis Bisnis RS PKU Muhammadiyah Blora}

Berangkat dari temuan-temuan penelitian yang dipetakan dalam matriks SWOT maka dapat dikembangkan Rencana Strategi Pelayanan untuk RS PKU Muhammadiyah Blora sebagai berikut:

Tabel 1 Rencana Strategi RS PKU Muhammadiyah Blora 2016-2020

\begin{tabular}{|c|c|c|c|c|}
\hline $\begin{array}{l}\text { Sasaran } \\
\text { Bisnis }\end{array}$ & Rencana Strategit & Tujuan Strategis & Indikator & Target \\
\hline $\begin{array}{l}\text { Pembelajaran } \\
\text { dan } \\
\text { pertumbuhan }\end{array}$ & $\begin{array}{l}\text { Efektifitasdiri ( } 7 \\
\text { habits) } \\
\text { danpembelajaran }\end{array}$ & $\begin{array}{l}\text { 1. Memahami dan } \\
\text { Menerapkan } \\
\text { budaya kerja di } \\
\text { RS PKU }\end{array}$ & $\begin{array}{l}\text { 1. Karyawan dapat } \\
\text { memahami dan } \\
\text { menerapkan } \\
\text { budaya kerja di } \\
\text { Rumah Sakit }\end{array}$ & $\begin{array}{l}\text { 1. Karyawan meemahami } \\
\text { dan menerapkan } \\
\text { budaya kerja: } \\
\text { - Tahun } 201650 \% \\
\text { - Tahun } 201770 \% \\
\text { - Tahun } 201880 \% \\
\text { - Tahun } 201990 \% \\
\text { - Tahun } 2020100 \%\end{array}$ \\
\hline & $\begin{array}{l}\text { Terwujudnya } \\
\text { Kultur } \\
\text { Muhammadiyah } \\
\text { di lingkungan } \\
\text { rumah sakit }\end{array}$ & $\begin{array}{l}\text { Karyawan dapat } \\
\text { menerapkan kultur } \\
\text { Muhammadiysh } \\
\text { dalam kehidupan } \\
\text { sehari-hari }\end{array}$ & $\begin{array}{l}\text { 1. Semua karyawan } \\
\text { mengikuti Baitul } \\
\text { Arqom }\end{array}$ & $\begin{array}{l}\text { 1. Karyawan RS PKU } \\
\text { sudah mengikuti Baitul } \\
\text { Arqom } \\
\text { - } \quad \text { Tahun } 201670 \% \\
\text { - } \quad \text { Tahun } 201790 \% \\
\text { - } \quad \text { Tahun } 2018100 \%\end{array}$ \\
\hline
\end{tabular}




\begin{tabular}{|c|c|c|c|c|}
\hline & & & 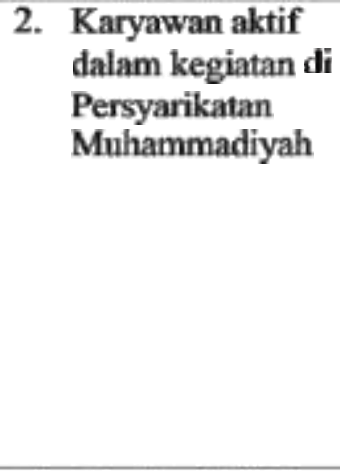 & $\begin{array}{l}\text { 2. Karyawan dapat } \\
\text { menerapkan } \\
\text { kultur } \\
\text { Muhammadiyah : } \\
\text { - } \quad \text { Tahun } 2017 \\
70 \% \\
-\quad \text { Tahun } 2018 \\
\quad 90 \% \\
-\quad \text { Tahun } 2019 \\
100 \%\end{array}$ \\
\hline & $\begin{array}{l}\text { Profesionalis } \\
\text { me }\end{array}$ & $\begin{array}{l}\text { Karyawanprofesion } \\
\text { aldi bidangnya }\end{array}$ & $\begin{array}{l}\text { 1. Kualitas SDM } \\
\text { a. Dokter } \\
\text { memiliki } \\
\text { Surat Irin } \\
\text { Prakitek } \\
\text { b. Perawat } \\
\text { memiliki } \\
\text { Surat Irin } \\
\text { Kerja } \\
\text { c. Bidan } \\
\text { memiliki } \\
\text { Surat Izin } \\
\text { Bidan } \\
\text { d. Memiliki } \\
\text { sertifikat } \\
\text { sesuai profesi } \\
\text { masing- } \\
\text { masing } \\
\text { 2. Knantitas SDM } \\
\text { Sesuai Standar } \\
\text { RS Tipe D }\end{array}$ & $\begin{array}{l}\text { 2. Tahun } 2016 \\
\text { kuantitas } \\
\text { SDM I00\% } \\
\text { sesuati RS } \\
\text { Tipe D }\end{array}$ \\
\hline $\begin{array}{l}\text { Proses } \\
\text { bisnis } \\
\text { internal } \\
\text { pelayan } \\
\text { an }\end{array}$ & $\begin{array}{l}\text { Terwujudny } \\
\text { a manajemen } \\
\text { mutu }\end{array}$ & 1. Rumah Sakit & $\begin{array}{l}\text { 1. Membentuk tim } \\
\text { audit mutu } \\
\text { pelayanan RS } \\
\text { dan tim } \\
\text { Akreditasi RS 4 } \\
\text { Bab } \\
\text { - Hak Pasien } \\
\text { dan } \\
\text { Keluarga } \\
\text { (HPK) } \\
\text { - Pencegahan } \\
\text { dan } \\
\text { Pengendalia } \\
\text { n Infeksi } \\
\text { (PPI) } \\
\text { Kualitas dan } \\
\text { Pendidikan } \\
\text { Staf (KPS) } \\
\text { Sasaran } \\
\text { Keselamata } \\
\text { n Pasien } \\
\text { (SKP) }\end{array}$ & $\begin{array}{l}\text { 1. Pada tahun } \\
2016: \\
\text { - Adanya } \\
\text { statuta RS } \\
\text { - Adanya } \\
\text { Renstra RS } \\
\text { - Dokumen } \\
\text { Akreditasi } 4 \\
\text { bab lengkap } \\
\text { - sosialisasi } \\
\text { Pedoman,Sta } \\
\text { ndar Prosedur } \\
\text { Operasional } \\
\text { (SPO) } \\
\text { Pelayanan RS } \\
\text { - implementasi } \\
\text { SPO } 4 \text { bab }\end{array}$ \\
\hline
\end{tabular}

Vol. 1 No. 2 Juli 2015 


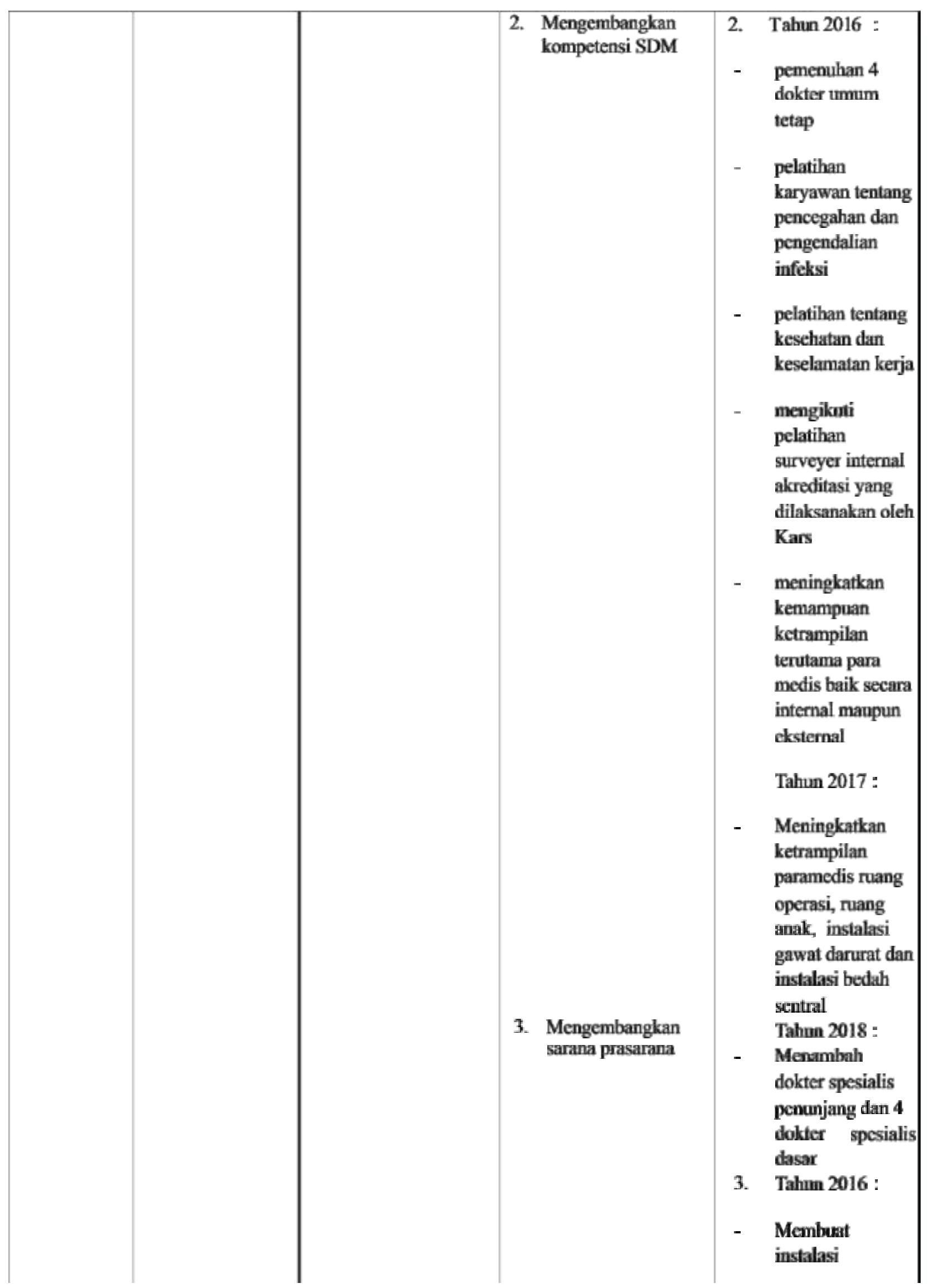

Vol. 1 No. 2 Juli 2015 


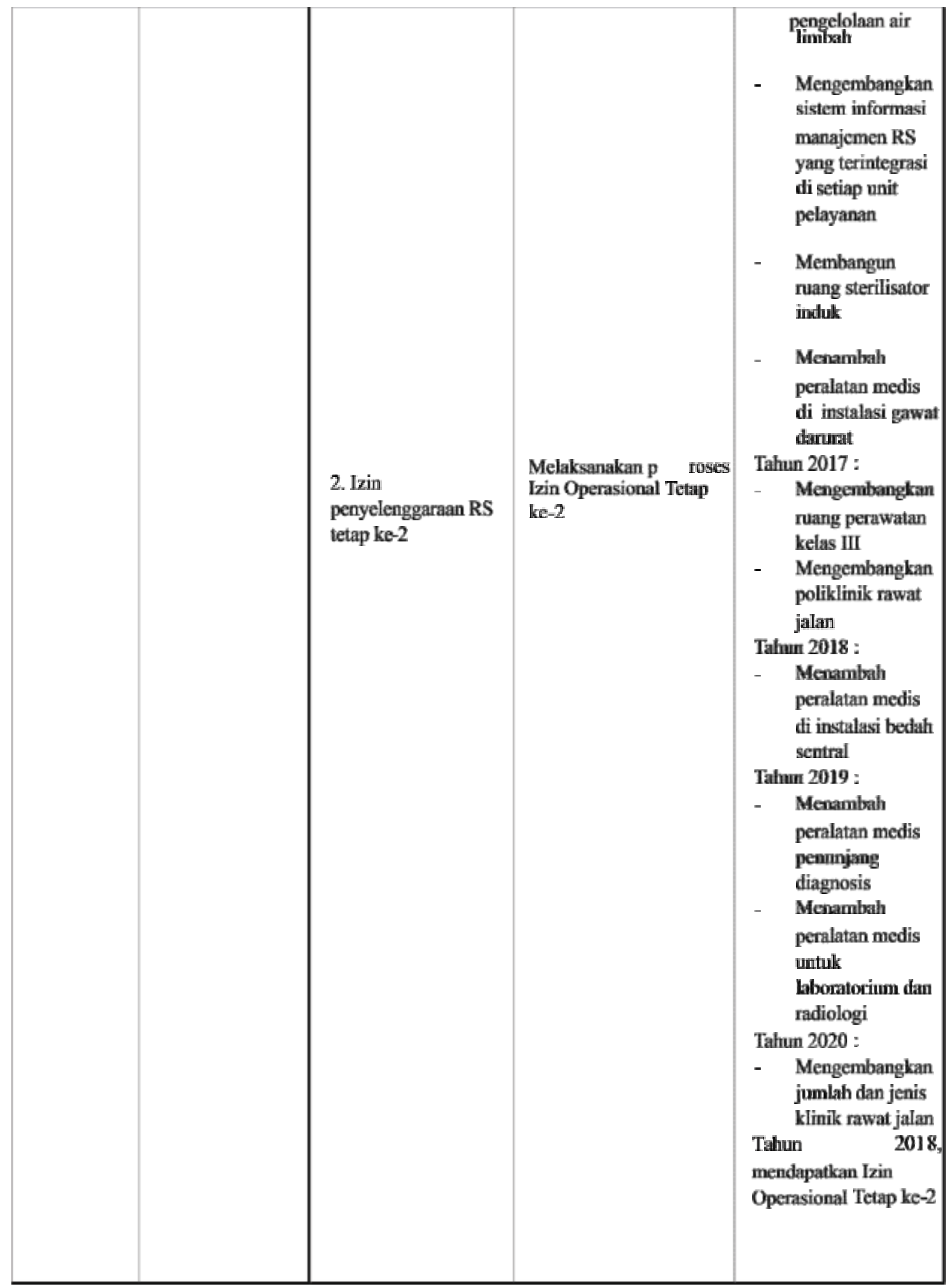




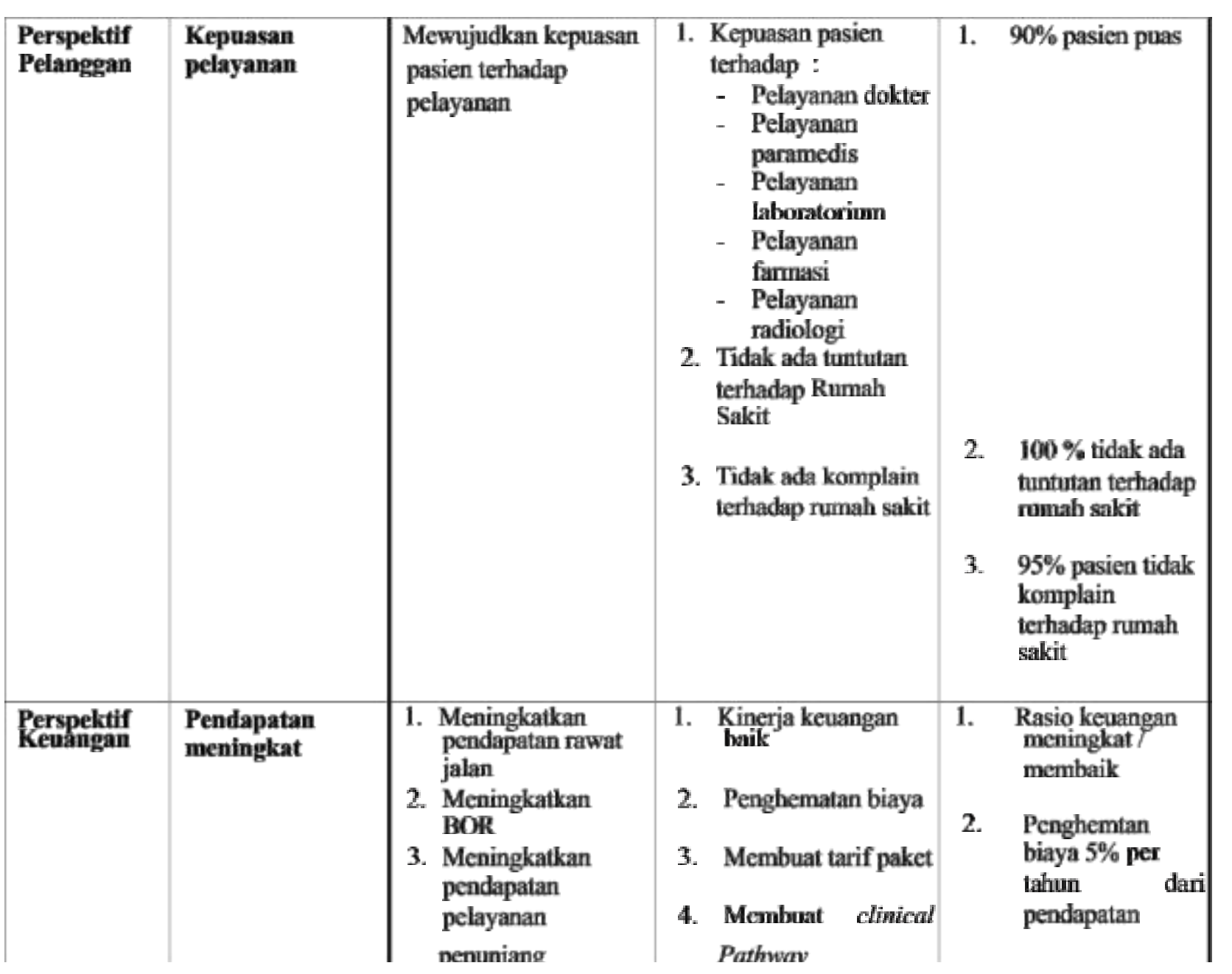

Sumber: Dikembangkan untuk Penelitian ini, 2015

Strategi bisnis RS PKU Muhammadiyah Blora yang telah dirumuskan di atas dapat digunakan untuk mengukur pencapaian hasil strategi guna mengetahui pencapaian kinerja RS PKU Muhammadiyah Blora yang dicapai melalui implementasi strategi bisnis yang telah dirumuskan.

\section{KESIMPULAN DAN SARAN}

\section{Kesimpulan}

Berdasar pada hasil analisis SWOT faktor internal (kekuatan dan kelemahan) dan faktor eksternal (peluang dan ancaman) maka menunjukkan posisi bisnis RS PKU Muhammadiyah Blora berada di kuadran I, yaitu Strategi Agresif oleh sebab itu, strategi bisnis pelayanan kesehatan RS PKU Muhammadiyah Blora adalah dengan menerapkan strategi kebijakan pertumbuhan agresif.

\section{Saran}

Mengacu strategi agresif yang dirumuskan dalam upaya pengembangan RS PKU Muhammadiyah langkah yang harus diambil adalah :

1. Mendayagunakan kekuatan secara optimal untuk meraih peluang yang dilakukan dengan mempercepat pembangunan baik ruang poliklinik rawat jalan untuk spesialis maupun penambahan ruang perawatan khususnya kelas III

2. Mendayagunakan kekuatan secara optimal untuk mengatasi ancaman yang dilakukan melalui pengembangan pelayanan dengan menambah jumlah pelayanan dan jenis pelayanan poliklinik spesialis 
serta fasilitas yang belum dimiliki oleh rumah sakit pesaing.

3. Mengatasi kelemahan untuk meraih peluang yang dilakukan dengan strategi Meningkatkan kemampuan dan ketrampilan terutama tenaga paramedis keperawatan maupun non keperawatan, pelaksanaan pelatihan bisa secara internal maupun eksternal Rumah Sakit, mengembangkan sistem informasi Rumah Sakit, dan melengkapi sarana pelayanan medis dan penunjang medis untuk mendukung pelayanan spesialistik, mengembangkan pelaksanaan sistem informasi RS.

4. Strategi keempat adalah untuk mengurangi kelemahan guna mengatasi ancaman yang dilakukan dengan cara membangun gedung sesuai dengan Master Plan dan kemampuan keuangan, meningkatkan pendidikan dan ketrampilan SDM serta membuat clinical pathway dengan tujuan pelaksanaan pelayanan sesuai standar pelayanan minimal dari kementerian kesehatan sehingga pelayanan berjalan dengan efektif dan efisien..

\section{Keterbatasan Penelitian}

Adapun keterbatasan yang ditemui dalam penelitian ini adalah bahwa penelusuran kekuatan, kelemahan, ancaman dan peluang di RS PKU Muhammadiyah Blora yang dilakukan dalam penelitian ini sebagian besar masih menggunakan data sekunder. Sedangkan pemanfaatan data primer dalam penelitian ini masih sangat terbatas dan kegunaannya masih terbatas untuk mendukung data sekunder yang diperoleh dalam penelitian ini.

\section{Agenda Penelitian Mendatang}

Penelitian mendatang yang diagendakan adalah sesuai dengan keterbatasan yang ditemukan dalam penelitian ini, yaitu pemanfaatan data primer dan sekunder secara seimbang.

Penggalian kekuatan, kelemahan, ancaman dan peluang di RS PKU MuhammadiyahBlora melalui dengan menggunakan data primer melalui Focus Group Discussion (FGD) dengan subyek penelitian harus dilakukan secara seimbang. Hal ini berfungsi untuk memperoleh informasi yang komprehensif dan adil.

\section{DAFTAR PUSTAKA}

1. Trisnantoro L, Aspek Strategis Manajemen Rumah Sakit; 2005

2. David \& Fred R, Manajemen Strategi: KonsepKonsep: Prentice Hall, New Jersey; 2006.

3. Dadang \& Hawari, Dimensi Religi dalam Praktek Psikiatri dan Psikologi, Jakarta: Fakultas Kedokteran UI; 2008.

4. Nurhapna \& Setya H, Pengaruh Perencanaan Strategis Terhadap Kinerja di Rumah Sakit, Jurnal Administrasi Kesehatan Indonesia Volume 2, 2014, 97: $91-100$

5. Nizar A \& Bambang H, Analisis Pengukuran Kinerja Rumah Sakit dengan Pendekatan Balanced Scorecard, Tesis, Malang: Program Studi Magister Ekonomi Universitas Brawijaya; 2012

6. Khadijah, Pengukuran Kinerja Rumah Sakit dengan Balanced Scorecard, Jurnal Administrasi dan Kebijakan Kesehatan, 2008, 90: 97-91.

7. Eko W \& Nur S, Penerapan Metode Balanced Scorecard Sebagai Tolok Ukur Penialian Kinerja Pada Organisasi Nirlaba, Jurnal, Semarang: Fakultas Ekonomi UNDIP; 2010.

8. Siregar \& Charler, Farmasi Rumah Sakit Teori dan Penerapan, Jakarta: EGC; 2004.

9. Sudra \& Rani Indradi, Statistik Rumah Sakit, Yogyakarta: Graha Ilmu; 2010

10.Chattap \& Nevizond, Diagnostic Manajemen, Jakarta: Serambi; 2007.

11.Mulyadi, Sistem Terpadu Pengelolaan Kinerja Personil Berbasis BSC, Yogyakarta: UPP STIM TKPN; 2007.

12.Ernawati \& David B, Pemetaan Renstra Bisnis dengan Analisis SWOT, Jurnal Administrasi Pembangunan, 2014, 211: 115-226.

13.Rangkuti \& Fredi, Analisis SWOT Teknik Membedah kasus Bisnis Reorientasi Konsep Perencanaan Strategis untuk Menghadapi Abad 21, Jakarta: Gramedia Pustaka Utama; 2003. 